\title{
Descriptions of vestibular migraine and Menière's disease in Greek and Chinese antiquity
}

Cephalalgia

2017, Vol. 37(4) 385-390

(C) International Headache Society 2016 Reprints and permissions: sagepub.co.uk/journalsPermissions.nav DOI: I0.II77/0333I024I6646755 journals.sagepub.com/home/cep

(S)AGE

\section{Doreen Huppert and Thomas Brandt}

\begin{abstract}
Background: Vestibular migraine and Menière's disease are two types of episodic vertigo syndromes that were already observed in Greek and Chinese antiquity. Descriptions first appeared in the work of the classical Greek physician Aretaeus of Cappadocia, who lived in the 2nd century AD, and in Huangdi Neijing, a seminal medical source in the Chinese Medical Classics, written between the 2 nd century BC and the 2 nd century AD.

Aim: The aim of this paper is to search in Aretaeus' book De causis et signis acutorum et chronicorum morborum and in Huangdi Neijing for descriptions of vertigo co-occurring with headache or ear symptoms that resemble current classifications of vestibular migraine or Menière's disease.

Results: Aretaeus describes a syndrome combining headache, vertigo, visual disturbance, oculomotor phenomena, and nausea that resembles the symptoms of vestibular migraine. In the Chinese book Huangdi Neijing the Yellow Thearch mentions the co-occurrence of episodic dizziness and a ringing noise of the ears that recalls an attack of Menière's disease. Conclusions: The descriptions of these two conditions in Greek and Chinese antiquity are similar to the vertigo syndromes currently classified as vestibular migraine and Menière's disease. In clinical practice it may be difficult to clearly differentiate between them, and they may also co-occur.
\end{abstract}

\section{Keywords}

Vestibular migraine, Menière's disease, headache, vertigo, Greek antiquity, Chinese antiquity, Aretaeus of Cappadocia, Yellow Thearch

Date received: 17 February 2016; revised: 2 March 2016; accepted: 7 March 2016

\section{Introduction}

During a systematic search of the literature for ancient descriptions of fear of heights and seasickness in the Chinese Medical Classics (1) and Greek antiquity $(2,3)$, we discovered two reports of vertigo syndromes that strikingly resemble today's definitions of vestibular migraine (VM) and Menière's disease (MD). These descriptions appeared in the book of Aretaeus of Cappadocia De causis et signis acutorum et chronicorum morborum and in Huangdi Neijing, the Yellow Thearch's Classic of Internal Medicine, a book that lays the theoretical foundation for Chinese medicine (Figure 1).

\section{Vestibular migraine in the Greek De causis et signis acutorum et chronicorum morborum}

The Greek physician Aretaeus was born in Asia Minor, Cappadocia, at the end of the reign of the emperor
Hadrian in the 2nd century AD. Little is known about his life, but it is thought that he studied in Alexandria and possibly practised in Rome. He was well versed in the science of Hippocrates, who was apparently an important role model for him. Eight books of his work contain extensive descriptions of the aetiology, features, and treatment of different diseases. Two were preserved: De causis et signis acutorum et chronicorum morborum and De therapia acutorum et chronicorum morborum. In the first of these he examines headache and differentiates, apparently for the first

Institute for Clinical Neurosciences and German Center for Vertigo and Balance Disorders, Ludwig-Maximilians-University, Germany

\section{Corresponding author:}

Doreen Huppert, Institute for Clinical Neurosciences and German Center for Vertigo and Balance Disorders, Ludwig-MaximiliansUniversity, Marchioninistrasse 15, 81377 Munich, Germany. Email: Doreen.Huppert@med.uni-muenchen.de 
time, between different forms of headache: a chronic

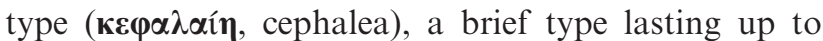

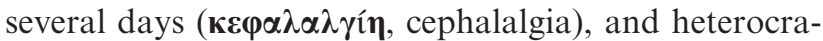

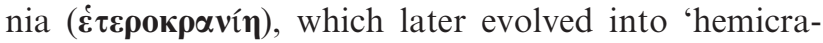
nias', from which our word 'migraine' is derived $(4,5)$. To the best of our knowledge no historical descriptions of VM have so far been published.

The term was first coined in 1999 (6). In the meantime VM has become a well-recognised medical entity and the most frequent cause of a spontaneous episodic vertigo syndrome. It is also the most common cause of episodic vertigo and dizziness in children (7). A chameleon of sorts among the episodic vertigo syndromes, $\mathrm{VM}$ is characterised by the variety of its clinical manifestations, especially as regards its duration (from minutes to days) and severity $(6,8-10)$.

Diagnostic criteria have been jointly formulated by the Committee for Classification of Vestibular Disorders of the Bárány Society and the Migraine Classification Subcommittee of the International Headache Society (IHS) (11, Table 1). VM is simple to diagnose if the attacks are generally or sometimes followed by headache and if the patient has a positive family or personal history of other types of migraine. The occurrence of symptoms like hypersensitivity to light and sound, a need for quiet, tiredness after the attack, an urge to urinate and an especially heightened susceptibility to motion sickness also makes the diagnosis easier. However, if headache is absent (in about $30 \%$ of cases; (6)), the attacks are more difficult to recognise. Most patients with VM also have mild central ocular motor disorders in the form of gaze-evoked nystagmus, saccadic smooth pursuit eye movements, or a positional nystagmus even in the attack-free interval
$(6,10)$. These disturbances are more severe during the attack and are often associated with postural instability.

Aretaeus draws attention to some of these features, especially in Book III in the chapter entitled 'Пepì

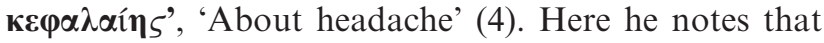
hemi-headache can be accompanied by vertigo, and even movements of the eyes:

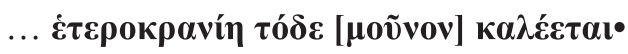

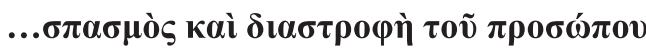

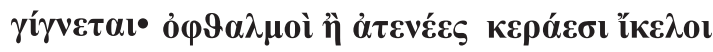

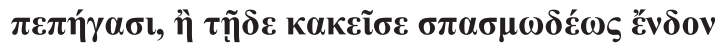

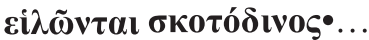

'This type of headache is called heterocrania....The face is distorted spasmodically, the eyes remain glassy and rigid like horns or move to and fro forcedly, and the patient is dizzy ...' (mentioned by Koehler and van de Wiel (5) and showing similarities to a German translation of 1790 (12)).

In this chapter Aretaeus points to other symptoms accompanying VM such as the patients' nausea, vomiting of black bile, and slumping down. They avoid light and feel relief when in the dark. Their sense of smell may be impaired, and they may even feel a weariness of life, 'taedium vitae' (based on a German translation from 1790 (12)).

In the next chapter, entitled 'Пврі $\boldsymbol{\sigma \kappa о} \tau \omega \mu \alpha \tau 1 \kappa \tilde{\omega} \boldsymbol{v}$ ' or 'About vertigo', a physical state is mentioned in which darkness befogs the eyes, the head whirls, and the ears hear sounds of a river murmuring; this condition is called $\boldsymbol{\sigma \kappa \kappa} \tau \omega \mu \boldsymbol{\alpha}$ (skotoma), i.e. vertigo (4). Moreover,

Table I. Current definitions of vestibular migraine and Menière's disease.

Vestibular migraine (a) At least five episodes with vestibular symptoms of moderate or severe intensity, lasting 5 minutes to 72
hours
(b) Current or previous history of migraine with or without aura according to the International Classification
of Headache Disorders (ICHD)
(c) One or more migraine features with at least $50 \%$ of the vestibular episodes:
- headache with at least two of the following characteristics: one-sided location, pulsating quality, moderate
or severe pain intensity, aggravation by routine physical activity
- photophobia and phonophobia
- visual aura
(d) Not better accounted for by another vestibular or ICHD diagnosis
(a) Two or more spontaneous episodes of vertigo, each lasting 20 minutes to I2 hours
(b) Audiometrically documented low- to medium-frequency sensorineural hearing loss in one ear, defining the
affected ear on at least one occasion before, during or after one of the episodes of vertigo
(c) Fluctuating aural symptoms (hearing, tinnitus, or fullness) in the affected ear
(d) Not better accounted for by another vestibular diagnosis

Adapted from Lempert et al. (II) for vestibular migraine and Lopez-Escamez et al. (22) for Menière's disease. 

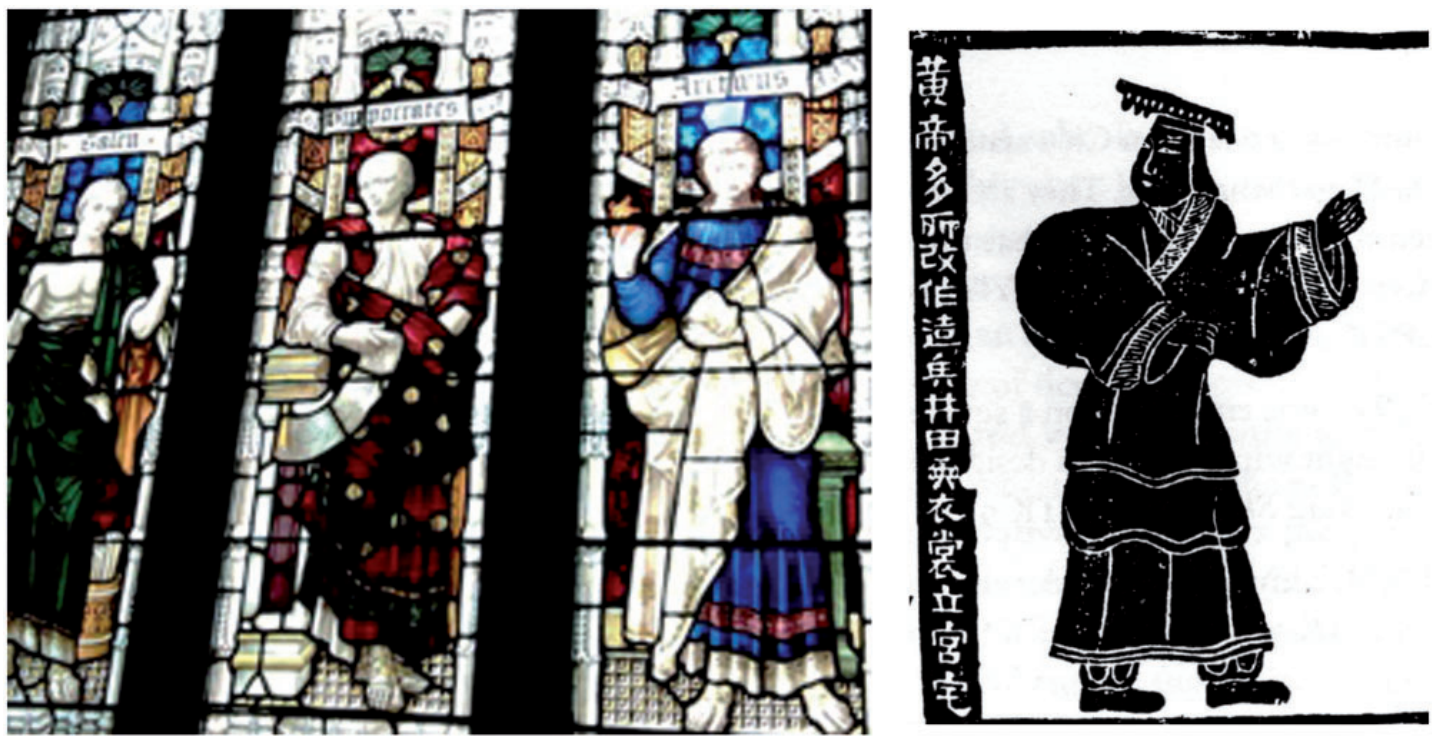

Figure I. Icons of classical medicine. I) Left: 'Galen, Hippocrates, and Aretaeus of Cappadocia' (from left to right) Window (The University of Sydney (34)). Right: The Yellow Emperor (Huangdi) as depicted in a tomb from the mid-2nd century AD (35).

this symptom may arise from the head (in the sense of headache - cephalea), and subsequently a severe condition develops. One has to be careful when interpreting the word 'scotoma' since the vestibular organ was not known at the time and the word was also used to mean 'to darken' or 'make dim-sighted'. The following attributes are used to describe the symptoms of scotoma:

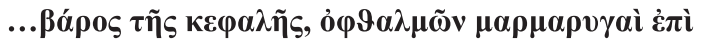

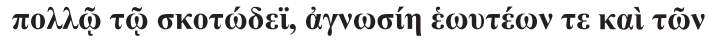

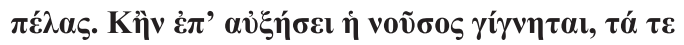

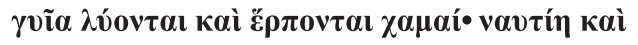

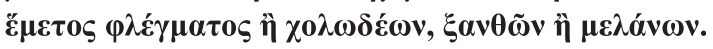

'...they sense a heaviness of the head and a pronounced darkening of the sense of sight; flying threads float before their eyes; they are aware of neither themselves nor those around them. And when the illness worsens, the forces that keep them upright become so weak that they crawl on the ground. They are overcome by a nausea and have to vomit watery, bilious, brightly yellow or black fluids' (based on a German translation from 1790 (12)).

The fundamental cause of scotoma is ascribed to dampness and cold:

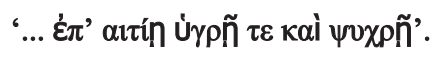

If the disease progresses and becomes intractable, then it may lead to other diseases such as melancholy, which may be preceded by nausea due to black bile. The classical authors tried to explain the cause of diseases within the framework of the humoral theory of Empedokles and
Aristoteles valid at the time: the four body fluids ( $\chi \mathbf{0} \lambda \dot{\eta}=$ yellow bile, $\quad \boldsymbol{\varphi} \lambda \dot{\varepsilon} \gamma \boldsymbol{\eta} \boldsymbol{\alpha}=$ phlegm, $\quad \boldsymbol{\mu} \dot{\varepsilon} \lambda \boldsymbol{\alpha} \iota \boldsymbol{v} \boldsymbol{\alpha}$ $\chi \mathbf{0} \lambda \dot{\eta}=$ black bile, $\alpha \tilde{\boldsymbol{i}} \boldsymbol{\mu} \boldsymbol{\alpha}=$ blood) were said to be out of balance (13). It was also used to explain the pathophysiology of seasickness (3). Therefore, the therapy recommended by Aretaeus was primarily a non-drug treatment like bloodletting, even for headache (14).

Nowadays the pathophysiology of migraine aura is usually considered to be a transient cortical 'spreading depression'. The symptoms of VM could be classified as brainstem aura in the sense of a non-cortical spreading depression (15). This fits findings of an animal study that proved the presence of spreading depression in the brainstem of rats (16). Animal studies also identified the locus coeruleus in the pontine brainstem to be the modulator of cerebral blood flow, in which the trigeminovascular system plays a central role along with neurogenic inflammatory reactions (17).

The interpretation of ancient texts presents problems. We are well aware of the limitations of medical historiography, in particular the retrospective diagnosis based on a few statements. Misinterpretations are possible not only due to translations of the original texts into contemporary languages but also due to completely different pathophysiological medical concepts (18).

\section{Menière's disease in the Chinese book Huangdi Neijing}

Huangdi Neijing has two parts, the 'Lingshu' and the 'Suwen' (19), both dating back to somewhere between the 2 nd century BC and the 2 nd century AD. The book presents the fundamental principles of Chinese 
medicine and provides lively descriptions of vertigo in different situations, e.g. at heights (1). The Yellow Thearch, Huang Di, is considered a cultural hero who bestowed the gift of medicine on the Chinese people. The book is mostly written in the form of dialogues between Huang Di and his physicians. One vertigo syndrome described in this book resembles MD.

The full picture of MD was first described by Prosper Menière in 1861 (20); it is the second most frequent cause of peripheral vestibular vertigo (21). MD is characterised by recurrent attacks of vertigo lasting minutes to hours with unilateral hearing loss, tinnitus and a feeling of fullness in one ear. Single attacks have no antecedent signs or recognisable precipitating factors. Approximately one-third of patients report an increase in tinnitus, ear pressure and hearing loss preceding the abrupt vertigo attacks. Monosymptomatic attacks that are purely cochlear or vestibular can occur, particularly at the beginning of MD. Over time most patients develop a progressive, persistent hypoacusis of the affected ear. In 2015 the diagnostic criteria for MD were reformulated by several otolaryngological societies working in collaboration with each other (22, Table 1). Vestibular drop attacks (Tumarkin's otolithic crisis) can also occur. They are characterised by sudden, recurring falls without loss of consciousness.

The Chinese character 眩 'dizziness' (xuan) is used to define a malfunction of the eyes in one of the ancient dictionaries (Shuowen Jiezi) dating from the 1st century. The character has a semantic indicator for 'eye" on the left side and the phonetic character 'xuan' on the right side. The latter stands not only for the semantic field dark, black, darkness, unsureness but also suggests how the character is pronounced. It thus evokes an image of how it becomes dark before the eyes during dizziness. Later the character stood for different types of dizziness, which were never clearly differentiated. Dizziness is interpreted to be an optical phenomenon and thus a malfunction of the eyes which is evident in the most important character for dizziness. Already in the 4th century BC the eyes were associated with the liver and its function in Chinese medicine. In the Huangdi Neijing Suwen is written (19): '[diseases with] wind [that causes] tumbling and dizziness belong without exception to the liver'. In all cases involving optical phenomena, the liver is immediately considered the cause.

Medieval European medicine observed correspondences between the heavenly bodies, the fluids in the human body, the temperaments and illnesses by means of which the phenomena of the macrocosm (world) and the microcosm (man) were ordered and divined. Likewise Chinese thinking connected climatic phenomena, cardinal directions, and calendric constellations with the actions of specific forces in the world and in the human body. Based on such systematic correspondences, this form of quasi-scientific, rational Chinese medical theory is called a medicine of correspondences. Dizziness was associated with the element/ phase wood, wind, the liver, and the eyes. The brain (in our modern meaning) is also associated with the phenomenon of dizziness. It is interesting that otherwise the brain virtually plays no role in traditional Chinese medicine: It is not one of the six yin (zang) nor one of the six yang organs (fu). More often it is described as a storage organ of a substance called and translated as 'marrow', which is equated with the spinal cord. Thus, in one of the oldest and most fundamental texts of Chinese medical theory there is nevertheless a conceptual connection of the brain with the phenomenon of dizziness. This suggests there was anatomical knowledge of a connection between the brain and the eyes, but not with the ears. It is interesting that this theoretical 'eye connection', which was apparently based on anatomy, was not thematised in later works. In general the anatomy of the human body was never, with very rare exceptions, investigated in China. In the Chinese view the flawless operation of bodily function is closely connected with all parts of the body receiving an adequate supply of specific body substances, such as blood and the vital force Qi. Various subdivisions included essences (jing), blood (xue) and Qi, conceived as implementations or various aggregate conditions of the same life force Qi. Assertions are made about the significance of the body substances in connection with dizziness. The only functional link between brain, eyes, and ears is related to hearing symptoms:

'If Qi is insufficient above, the brain is not sufficiently filled by it, the ears suffer a ringing noise, the head is bent low by it, the eyes [experience] dizziness' (19).

Here the brain is to be understood as the 'sea of marrow', i.e. the storage site of the marrow - a substance of the body. Thus, dizziness occurs with tinnitus and an imbalance of the head due to deficient Qi in the head. The following citation from the chapter 'Discussion of the sea' refers to the same subject matter: 'If the sea of marrow is not sufficiently filled, the brain begins rotating around, the ears ringing, the calves/shins suffer from sour pains and the veil-dizziness (xuanmao) appears, the eyes can see nothing and passivity and hypersomnia occur' (19).

This combination of a ringing in the ears and dizziness is similar to the current diagnostic criteria for MD, but the pathophysiological explanations differ from our current views. The pathophysiological mechanism underlying the condition was not known in ancient China, since the function of the vestibular organ had not yet been discovered. The clinical history of the 
vestibular system spans a period of only about 100 years (2). The aetiology and pathophysiology of MD still remain unclear (23-25), although vascular, neuroimmunological, or inflammatory aetiologies have been discussed. Evidence for a viral cause of MD is still equivocal (26). The pathognomonic histopathological finding is an endolymphatic hydrops (27) that may develop as a result of a relatively too high production or too low resorption of endolymph. The elevated pressure causes the endolymphatic membrane to rupture or the pressure-sensitive unselective cation channels to open (28). As a result the potassium concentration in the perilymph rises, causing the attack: first due to excitation and then to depolarisation of the vestibulocochlear nerve fibres. Evidence of endolymphatic hydrops can be found in post-mortem temporal bone studies (27) and also in vivo on high-resolution magnetic resonance imaging (MRI) after transtympanic gadolinium injection, since gadolinium primarily diffuses into the perilymphatic space (29). This technique has been considerably improved and now provides a supportive diagnostic tool $(30,31)$.

\section{Conclusion}

We discussed these two vestibular forms of vertigo jointly because in clinical practice they often resemble each other: Both have attacks of variable duration and the attacks reoccur. Sometimes it may be difficult to clearly differentiate between VM and MD, especially if attacks of VM occur without headache as is the case in $30 \%$ of patients (6) or if attacks of MD occur without ear symptoms, especially at the beginning of MD (32). The duration of vertigo attacks alone does not permit a reliable distinction. It is important to stress that $60 \%$ of patients with MD also fulfil the diagnostic criteria for VM and vice versa (33). Moreover, both diagnoses (uni- or bilateral MD and migraine with and without aura) often coincide in $56 \%$ compared with $25 \%$ in an age-matched control group (33). Frequently, the diagnosis can be made only on the basis of the patient's response to therapy and on the course of the disease. However, a progressive hearing loss is evident in patients with MD, whereas vestibular migraine patients have normal hearing results.

\section{Article highlights}

- In the 2nd century AD Aretaeus of Cappadocia describes in his book De causis et signis acutorum et chronicorum morborum an association of hemicrania with vertigo, nystagmoid eye movements, and nausea that resembles our current view of vestibular migraine.

- In the Chinese Medical Classics Huangdi Neijing from the 2nd century BC to the 2nd century AD, the Yellow Thearch reports on an episodic disorder with dizziness involving the connection between eyes and brain and associated with a ringing noise in the ears that recalls a Menière's attack.

- The ancient view of the pathophysiological mechanism underlying both conditions was based on humoral processes: the theory of Emedokles and Aristoteles in ancient Greece and the medicine of correspondences with dysfunction of the vital force Qi in ancient China.

\section{Acknowledgement}

The authors thank Matthias Bauer for his search in the antique Chinese literature and Judy Benson for copyediting the manuscript. D. Huppert conceived and designed the study, analysed and interpreted the classical texts, and wrote the paper. T. Brandt designed the study, analysed and interpreted the classical texts, and wrote the paper.

\section{Declaration of conflicting interests}

The authors declared no potential conflicts of interest with respect to the research, authorship, and/or publication of this article.

\section{Funding}

The authors disclosed receipt of the following financial support for the research, authorship, and/or publication of this article: This work was supported by funds from the German Federal Ministry of Education and Research
(BMBF grant code 01 EO 0901) and the Hertie Foundation.

\section{References}

1. Bauer M, Huppert D and Brandt T. Fear of heights in ancient China. J Neurol 2012; 259: 2223-2225.

2. Huppert D, Benson J, Krammling B, et al. Fear of heights in Roman antiquity and mythology. J Neurol 2013; 260: 2430-2432.

3. Huppert D, Oldelehr H, Krammling B, et al. What the ancient Greeks and Romans knew (and did not know) about seasickness. Neurology 2016; 86: 560-565.

4. Hude C (ed.). Aretaeus. Corpus Medicorum Graecorum II. Berlin: Akademie-Verlag, 1958.

5. Koehler PJ and van de Wiel TW. Aretaeus on migraine and headache. J Hist Neurosci 2001; 10: 253-261.

6. Dieterich $\mathrm{M}$ and Brandt $\mathrm{T}$. Episodic vertigo related to migraine (90 cases): Vestibular migraine? J Neurol 1999; 246: 883-892. 
7. Jahn K, Langhagen $\mathrm{T}$ and Heinen F. Vertigo and dizziness in children. Curr Opin Neurol 2015; 28: 78-82.

8. Neuhauser H, Leopold M, von Brevern $\mathbf{M}$, et al. The interrrelations of migraine, vertigo and migrainous vertigo. Neurology 2001; 56: 436-441.

9. Strupp M, Versino M and Brandt T. Vestibular migraine. Handb Clin Neurol 2010; 97: 755-771.

10. Radtke A, Neuhauser H, von Brevern M, et al. Vestibular migraine - validity of clinical diagnostic criteria. Cephalalgia 2011; 31: 906-913.

11. Lempert T, Olesen J, Furman J, et al. Vestibular migraine: Diagnostic criteria. J Vest Res 2012; 22: 167-172.

12. Aretaeus. Aretäus des Kapadoziers, von den Ursachen und Kennzeichen rascher und langwieriger Krankheiten. Vier Bücher. Wien: Wappler Verlag, 1790.

13. Schöner E. Das Viererschema in der antiken Humoralpathologie. Wiesbaden: Steiner, 1964.

14. Koehler PJ and Boes CJ. A history of non-drug treatment in headache, particularly migraine. Brain 2010; 133: 2489-2500.

15. Furman JM, Marcus DA and Balaban CD. Migrainous vertigo: Development of a pathogenetic model and structured diagnostic interview. Curr Opin Neurol 2003; 16 : 5-13.

16. Richter F, Bauer R, Lehmenkühler A, et al. Spreading depression in the brainstem of the adult rat: Electrophysiological parameters and influences on regional brainstem blood flow. J Cereb Blood Flow Metab 2008; 28 : 984-994.

17. Goadsby PJ. The pharmacology of headache. Prog Neurobiol 2000; 62: 509-525.

18. Karenberg A. Retrospective diagnosis: Use and abuse in medical historiography. Prague Med Rep 2009; 110: 140-145.

19. Wang $\mathrm{H}$ (ed.) Huangdi neijing yanjiu dacheng (The great compendium of the research on the Huangdi Neijing). Beijing: Beijing chubanshe, 1997.

20. Menière P. Mémoire sur les lesions de l'oreille interne donnant lieu à des symptômes de congestion cérébrale apoplectiforme. Gaz Méd Paris Sér 3 1861; 16: 597-601.

21. Neuhauser HK. Epidemiology of vertigo. Curr Opin Neurol 2007; 20: 40-46.
22. Lopez-Escamez JA, Carey J, Chung WH, et al. Diagnostic criteria for Menière's disease. J Vest Res 2015; 25: 1-7.

23. Minor LB, Schessel DA and Carey JP. Menière's disease. Curr Opin Neurol 2004; 17: 9-16.

24. Semaan MT, Alagramam KN and Megerian CA. The basic science of Menière's disease and endolymphatic hydrops. Curr Opin Otolaryngol Head Neck Surg 2005; 13: 301-307.

25. Saijadi H and Paparella MM. Meniere's disease. Lancet 2008; 372: 406-414.

26. Beyea JA, Agrawal SK and Parnes SL. Recent advances in viral inner ear disorders. Curr Opin Otolaryngol Head Neck Surg 2012; 20: 404-408.

27. Merchant SN, Adams JC and Nadol Jr JB. Pathophysiology of Meniere's syndrome: Are symptoms caused by endolymphatic hydrops? Otol Neurotol 2005; 26: 74-81.

28. Yeh TH, Herman P, Tsai MC, et al. A cationic nonselective stretch-activated channel in the Reissner's membrane of the guinea pig cochlea. Am J Physiol 1998; 274(3 Pt 1): C566-C576.

29. Nakashima T, Naganawa S, Sugiura M, et al. Visualization of endolymphatic hydrops in patients with Meniere's disease. Laryngoscope 2007; 117: 415-420.

30. Pierce NE and Antonelli PJ. Endolymphatic hydrops perspectives 2012. Curr Opin Otolaryngol Head Neck Surg 2012; 20: 416-419.

31. Gürkov R, Flatz W, Louza J, et al. In vivo visualization of endolymphatic hydrops in patients with Meniere's disease: Correlation of audiovestibular function. Eur Arch Otorhinolaryngol 2011; 268: 1743-1748.

32. Brandt T, Dieterich M and Strupp M. Vertigo and dizziness: Common complaints, 2nd edn. London: Springer, 2013.

33. Radtke A, Lempert T, Gresty MA, et al. Migraine and Menière's disease: Is there a link? Neurology 2002; 59: 1358-1360.

34. 'Galen, Hippocrates, and Aretaeus of Cappadocia' Window, The University of Sydney, Medievalism in Australian Cultural Memory, http://ausmed.arts.uwa.edu.au/items/show/723 (accessed 18 January 2016).

35. Birrell A. Chinese mythology: An introduction. Baltimore and London: The John Hopkins University Press, 1993, p.48. 